\title{
RECENT SASKATCHEWAN GRIZZLY
}

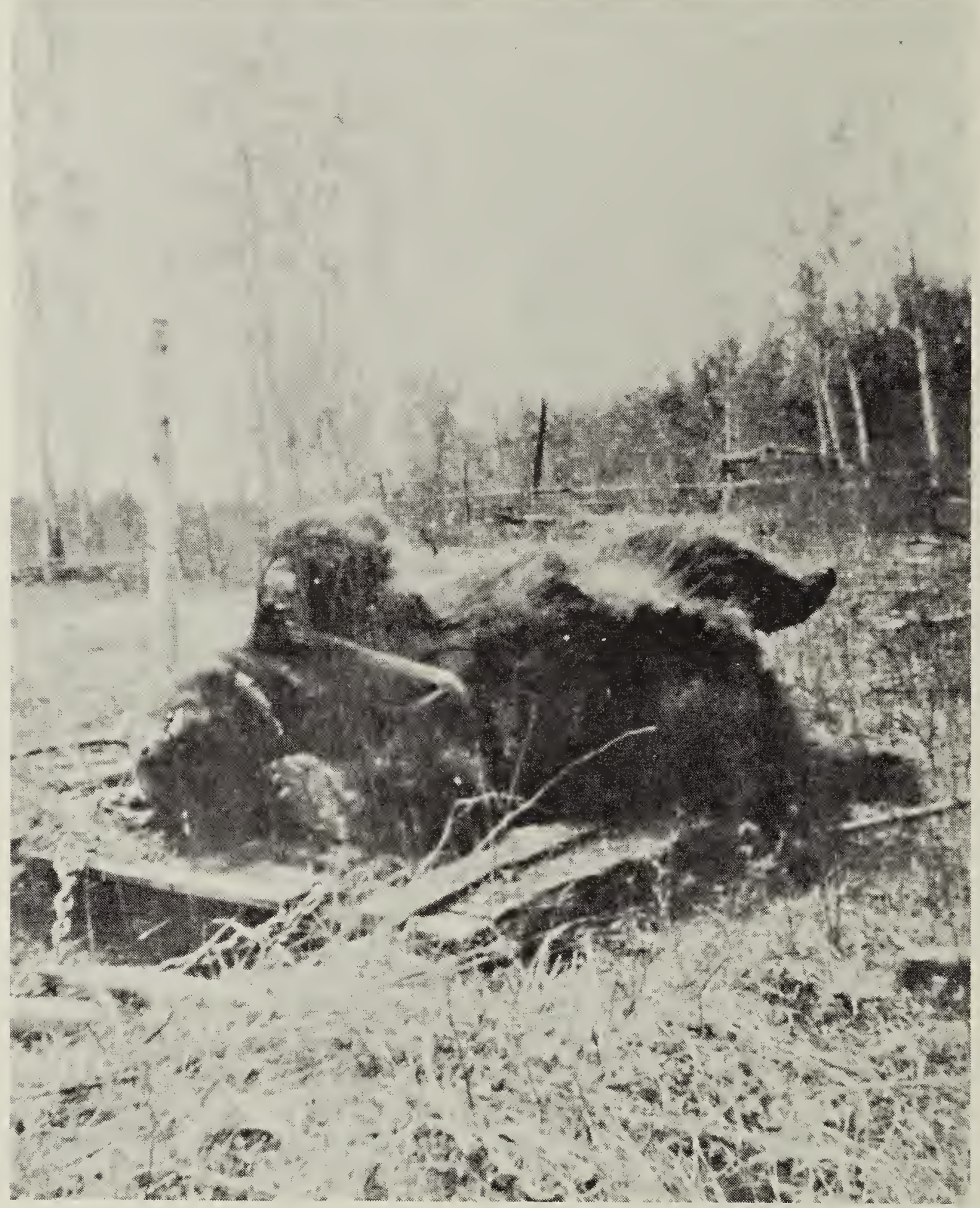

Veillardville, Saskatchewan, about 1939

Photo by Gerry Murdock

The above photograph of a bear is a second view of the one killed by a set-gun at Veillardville in 1938 or 1939, as previously reported by Tom White (see Blue Jay, 23:139-140 for further details). The editors regret having omitted this photograph from Mr. White's article on the Grizzly, for this is the photograph which was identified by Dr. Phillip M. Youngman, Curator of Mammals, National Museum of Canada, as almost cer- tainly a Grizzly (pers. corres., T. White, 1964). In October, 1965, at the Annual Meeting of the Saskatchewan Natural History Society at Saskatoon, Al Oeming, guest speaker and a considerable authority on Grizzlies, examined this photograph and said he was certain it was a Grizzly. The length and shape of the ears, according to Oeming, are particularly diagnostic, but the length of the claws and teeth are also useful characters. 